appropriate use remained constant across the different prescribing groups during the study period (Supplementary Fig. 1 online).

In this study, implementing peer comparison had no impact on the appropriateness or overall rates of carbapenem use among hospitalized patients. Our study highlights the complexities of implementing this strategy on inpatient settings. The use of peer comparison has been shown to decrease antibiotic prescribing in outpatient settings ${ }^{4,5}$; however, prescribing dynamics are different in inpatient settings, where the physician who initially prescribes an antibiotic may not be responsible for patient care in subsequent days and $>1$ medical service may be involved in management. This setting poses a challenge from accountability and logistic perspectives.

The baseline use of the antibiotic class targeted could influence the results of this type of intervention. Allen et al. ${ }^{6}$ conducted a quasiexperimental before-and-after study targeting high-volume fluoroquinolone prescribers across 16 community hospitals in Florida. All hospitals had ASPs. Individuals belonging to 3 cohorts (ie, internal medicine, family medicine, and hospitalists; intensivists; and infectious diseases specialists) were provided with individual and facility-specific peer cohort percentage of total antibiotic days of therapy attributable to fluoroquinolones, as well as education on decreasing fluoroquinolone use. Fluoroquinolone use declined by $29 \%$ in the postintervention period, with larger changes seen in facilities with the highest baseline use. In contrast to this study, our intervention targeted a different antibiotic class with low baseline use.

The limitations of our study include its observational design and that it was conducted at a single center. Furthermore, our intervention did not include all hospital providers prescribing carbapenems. However, we included the physician groups responsible for the majority of carbapenem DOTs at our institution.

In conclusion, we found no impact on trends of carbapenem use following the addition of peer comparison to a well-established inpatient ASP using prospective review and feedback as its main strategy. Future studies can help determine whether this strategy could be applied to other antibiotics classes or specific syndromes among hospitalized patients.

Supplementary material. To view supplementary material for this article, please visit https://doi.org/10.1017/ice.2019.377

Acknowledgments. None.

Financial support. No financial support was provided relevant to this article.

Conflicts of interest. All authors report no conflicts of interest relevant to this article.

\section{References}

1. Barlam TF, Cosgrove SE, Abbo LM, et al. Implementing an antibiotic stewardship program: guidelines by the Infectious Diseases Society of America and the Society for Healthcare Epidemiology of America. Clin Infect Dis 2016;62:e51-e77.

2. The Core Elements of Outpatient Antibiotic Stewardship. Centers for Disease Control and Prevention website. https://www.cdc.gov/antibioticuse/community/pdfs/16_268900-A_CoreElementsOutpatient_508.pdf. Published 2016. Accessed October 21, 2019.

3. Spivak ES, Cosgrove SE, Srinivasan A. Measuring appropriate antimicrobial use: attempts at opening the black box. Clin Infect Dis 2016;63:1639-1644.

4. Gerber JS, Prasad PA, Fiks AG, et al. Effect of an outpatient antimicrobial stewardship intervention on broad-spectrum antibiotic prescribing by primary care pediatricians: a randomized trial. JAMA 2013;309:23452352.

5. Meeker D, Linder JA, Fox CR, et al. Effect of behavioral interventions on inappropriate antibiotic prescribing among primary care practices: a randomized clinical trial. JAMA 2016;315:562-570.

6. Allen JM, Dunn R, Bush J. Effect of prescriber peer comparison reports on fluoroquinolone use across a 16-facility community hospital system. $J$ Am Coll Clin Pharm 2019:6.

\title{
Detection of the emergence of mcr-1-mediated colistin-resistant Escherichia coli and Klebsiella pneumoniae through a hospital-based surveillance in an oncology center in eastern India
}

\author{
Samadrita Roy $\mathrm{MSc}^{1}$, Parijat Das MSc, $\mathrm{PhD}^{1}$, Surojit Das MSc, $\mathrm{PhD}^{2}$, Subhanita Roy $\mathrm{MSc}^{1}$, Soumik Pal MSc ${ }^{1}$, \\ Vinitha Mary Joy MD ${ }^{1}$, Sudipta Mukherjee MD, IDCCM, FNB, EDICM ${ }^{3}$, Arpita Bhattacharyya MRCP4, \\ Gaurav Goel MD, DNB, MNAMS ${ }^{1}$, Sanjay Bhattacharya MD, DNB, FRCPath ${ }^{1}$ (1), Purva Mathur MD ${ }^{5}$, \\ Kamini Walia PhD, $\mathrm{MPH}^{6}$ and Mammen Chandy MD, FRCPA, FRACP, FRCP \\ ${ }^{1}$ Department of Microbiology, Tata Medical Center, Kolkata, India, ${ }^{2}$ Department of Biomedical Laboratory Science and Management, Vidyasagar University, West \\ Bengal, India, ${ }^{3}$ Department of Anaesthesia \& Critical Care Medicine, Tata Medical Center, Kolkata, India, ${ }^{4}$ Department of Paediatric Hematology and Oncology, \\ Tata Medical Center, Kolkata, India, ${ }^{5}$ Department of Laboratory Medicine, JPNA Trauma Centre, All India Institute of Medical Sciences, New Delhi, India, ${ }^{6}$ Indian \\ Council of Medical Research, New Delhi, India and ${ }^{7}$ Department of Clinical Hematology, Tata Medical Center, Kolkata, India
}

Author for correspondence: Sanjay Bhattacharya, MD,

Tata Medical Center, Kolkata, India. E-mail: sanjay.bhattacharya@tmckolkata. com

Cite this article: Roy S, et al. (2020). Detection of the emergence of $m c r-1$-mediated colistin-resistant Escherichia coli and Klebsiella pneumoniae through a hospital-based surveillance in an oncology center in eastern India. Infection Control \& Hospital Epidemiology, 41: 378-380, https://doi.org/10.1017/ice.2019.363
To the Editor-The global emergence of colistin-resistant Enterobacteriaceae through the plasmid-mediated $\mathrm{mor}$ gene has raised concerns with regard to spread of antimicrobial resistance and infection control. ${ }^{1}$ There are several mechanisms of colistin resistance. ${ }^{2}$ However, the molecular epidemiology of colistin resistance in clinically relevant gram-negative isolates is poorly defined in India, a country that is large and populous and is also a major 
Table 1. Distribution of Carbapenemase- and Colistin-Resistant $m c r-1$ Gene in the Samples Studied (N = 198)

\begin{tabular}{|c|c|c|c|c|c|c|c|c|c|c|c|c|c|}
\hline \multirow[b]{2}{*}{ Sample } & \multicolumn{4}{|c|}{ Klebsiella pneumoniae } & \multicolumn{3}{|c|}{ E. coli } & \multirow{2}{*}{$\begin{array}{c}\begin{array}{c}\text { Enterobacter } \\
\text { ssp. }\end{array} \\
\\
\text { bla }_{\mathrm{NDM}} \\
+ \text { bla }_{\mathrm{OXA}-48}\end{array}$} & \multicolumn{3}{|c|}{ Acinetobacter spp. } & \multirow{2}{*}{$\begin{array}{c}\text { Pseudomonas } \\
\text { bla }_{\mathrm{NDM}}\end{array}$} & \multirow{2}{*}{$\begin{array}{l}\text { Carba- } \\
\text { penemase } \\
\text { Negative }\end{array}$} \\
\hline & $\begin{array}{c}b^{b l a_{\mathrm{NDM}}} \\
+b \text { la }_{\mathrm{OXA}-} \\
\quad 48\end{array}$ & $b l a_{\mathrm{OXA}-48}$ & $b / a_{\mathrm{KPC}}$ & $b l a_{\mathrm{NDM}}$ & $b / a_{\mathrm{OXA}-48}$ & $\begin{array}{l}b l a_{\mathrm{NDM}} \\
+b l a_{\mathrm{VIM}} \\
\end{array}$ & $\begin{array}{c}\text { No Carbape- } \\
\text { nemase Genes } \\
\text { Detected }\end{array}$ & & $b l a_{\mathrm{OXA}-48}$ & $b l a_{\mathrm{OXA}-58}$ & $\begin{array}{c}b^{b l a_{\mathrm{NDM}}} \\
+b a_{\mathrm{OXA}-} \\
\quad 58\end{array}$ & & \\
\hline $\begin{array}{l}\text { Respiratory } \\
\text { samples }\end{array}$ & 12 & 17 & 0 & 2 & 0 & 0 & & 24 & 0 & 0 & 1 & 0 & 5 \\
\hline Urine & 0 & 17 & 1 & 1 & 1 & 1 & & 0 & 0 & 0 & 0 & 2 & 28 \\
\hline Blood & 6 & 14 & 0 & 1 & 0 & 0 & & 0 & 0 & 2 & 1 & 0 & 22 \\
\hline Pus & 0 & 7 & 0 & 0 & 0 & 0 & & 0 & 1 & 0 & 0 & 0 & 15 \\
\hline Body fluid & 2 & 2 & 0 & 0 & 0 & 0 & & 0 & 0 & 0 & 0 & 0 & 15 \\
\hline$m c r-1$ & 0 & 1 & 0 & 0 & 1 & 0 & 1 & 0 & 0 & 0 & 0 & 0 & 0 \\
\hline
\end{tabular}

Note: carbapenemase genes tested included: $b l a_{\mathrm{NDM}}, b l a_{\mathrm{KPC}}, b l a_{\mathrm{IMP}}, b l a_{\mathrm{VIM}}$, blaOXA-48, 23,24,58.

trading center and an international tourism destination. ${ }^{3,4}$ Here, we document 2 cases of $\mathrm{mcr}$-gene-mediated colistin resistance in Enterobacteriaceae from an oncology center in eastern India.

\section{Case 1}

In June 2018, we isolated Escherichia coli in the urine of a 51-year-old woman from West Bengal, India, with metastatic carcinoma of lung. The E. coli isolate (detected while she was in the community) was positive for $b l a_{\mathrm{OXA}-48}$ and $m c r-1$ (confirmed by PCR and DNA sequencing). The minimum inhibitory concentration (MIC) for colistin was $4 \mu \mathrm{g} / \mathrm{mL}$. In September 2019, while she was in the hospital, we detected Klebsiella pneumoniae from endotracheal aspirate which was $b a_{\text {OXA-48 }}$ and $m c r-1$ positive (colistin MIC, $16 \mu \mathrm{g} / \mathrm{mL}$ ). The patient was treated with fosfomycin. The patient had a diagnosis of diabetes mellitus and had several medical devices (urinary catheter, tracheostomy, central line). Carbapenemase-resistant isolates were detected previously, and she had received treatment in the past with meropenem and colistin.

\section{Case 2}

In an 8-year-old girl from Bangladesh with acute lymphoblastic leukemia, we detected, from left buttock wound swab, a carbapenem-sensitive but colistin-resistant Escherichia coli (positive for $m c r-1)$ with an MIC of $8 \mu \mathrm{g} / \mathrm{mL}$.

These 2 cases were part of a prospective surveillance for mcr-1-5 genes conducted in Tata Medical Center, Kolkata, India, a 183-bed oncology center where patients are mainly from the state of West Bengal in India but also from neighboring states in India and countries such as Bangladesh and Bhutan. The inclusion criteria for testing of $m c r-1-5$ genes by polymerase chain reaction (PCR) was the detection of colistin resistance (MIC $\geq 2 \mu \mathrm{g} / \mathrm{mL}$ ) using the microbroth dilution method according to the European Committee on Antimicrobial Susceptibility Testing (EUCAST) and Clinical Laboratory Standards Institute (CLSI) guidelines. If found to be carbapenem resistant, the isolates were also screened for the presence of the following carbapenemaseassociated genes: $b l a_{\mathrm{NDM}-1}, \quad b l a_{\mathrm{VIM}}, b l a_{\mathrm{IMP}}, \quad b l a_{\mathrm{OXA} 48-\mathrm{like}, 23,24,58}$, $b l a_{\mathrm{KPC}}$. Identification of the isolates was performed using the Vitek2 system (bioMèrieux, Marcy-l'Étoile, France), and $m c r-1-5$ genes were tested using in-house end-point multiplex PCR. If positive, they were confirmed by Sanger-based DNA sequencing.
The results of this surveillance (conducted between August 2017 to October 2019) are presented in online Fig. 1 and Table 1.

Among colistin-resistant mechanisms, plasmid-mediated resistance is a major cause of global concern because of the potential for transfer of colistin-resistance genes to susceptible strains. These genes were first reported in E. coli isolated in China. ${ }^{1}$ The mechanism of $m c r$-mediated colistin resistance is as follows. Encoded $m c r-1$ protein is a member of the phosphoethanolamine transferase enzyme family; $\mathrm{mcr}$ acquisition results in the addition of phosphoethanolamine to lipid $\mathrm{A}$, and thereby to a more cationic lipopolysaccharide, which contributes to acquired colistin resistance in Enterobacteriaceae. ${ }^{5}$ Isolates carrying the $m c r-1$ gene demonstrate resistance to colistin displaying 4-8-fold increase in colistin MIC. ${ }^{5}$ Some plasmids containing the $m c r-1$ gene carry other genes that are resistant to antibiotics, such as $\beta$-lactams, aminoglycosides, quinolones, sulfonamides, tetracyclines, and fosfomycin. ${ }^{5}$ The $m c r$ gene has also been identified in Enterobacteriaceae isolates, which carry such carbapenemase genes as $b l a_{\mathrm{NDM} 1}, b l a_{\mathrm{NDM} 5}, b l a_{\mathrm{NDM} 9}, b l a_{\mathrm{OXA} 48}, b l a_{\mathrm{KPC} 2}$, and $b l a_{\mathrm{VIM} 1}{ }^{6}$ Studies have shown $m c r-2-$ mediated colistin resistance in $E$. coli isolates from European countries, whereas $m c r-3$ has been widely identified in Enterobacteriaceae (mainly E. coli) and Aeromonas spp from Asia, Europe, and North America., ${ }^{7,8}$ The $m c r-4$ and $m c r-5$ genes were first characterized in Salmonella and E. coli from European countries. ${ }^{9,10}$ Currently from India, only 1 report of $\mathrm{mcr}$-mediated colistin resistance in Klebsiella pneumoniae has been published. ${ }^{3}$ In 2017, Borowiak et $\mathrm{al}^{10}$ reported a new gene of the $m c r$ family from Salmonella paratyphi B that were carried in transposons instead of plasmids.

The emergence of colistin resistance is a cause for concern for both clinicians and patients, particularly in countries with high rates of carbapenem- and/or colistin-resistant Enterobacteriaceae such as China and India. We are not aware of any report of the prevalence of $m c r$-mediated colistin resistance in the immunocompromised cancer patient population in India.

Because the $\mathrm{mor}$ gene is plasmid mediated, the infection prevention and control challenges are significant. Using the PCR-based method, we have tried to develop a relatively low cost and feasible system to detect $\mathrm{mcr}$-mediated mechanisms of colistin resistance. The cost of $m c r$ gene detection is USD $\$ 7$ for the multiplex screening PCR and USD \$20 for Sanger-based DNA sequencing per isolate.

This study is important in several aspects. We have shown that mor-1-mediated colistin resistance may occur independent of 
carbapenem resistance (i.e. case 2). The occurrence of these resistance mechanisms in immunocompromised cancer patients who have extensive healthcare and antibiotic exposure as well as hospital admission episodes increases the risk of infection spread in healthcare settings as well as in community (case 1). The second case shows that this resistance phenomenon can be found even in children. These cases are, to the best of our knowledge, the first reports of such infections from eastern India. Because of the proximity of this region to highly populous areas and to international trade, tourism, and travel, the likelihood of international dissemination may be high. Surveillance of $\mathrm{mcr}$-mediated colistin resistance may reveal more cases and facilitate better infection control.

Supplementary material. To view supplementary material for this article, please visit https://doi.org/10.1017/ice.2019.363

Acknowledgments. We thank the Indian Council of Medical Research for supporting the study.

Financial support. This study was supported by the Indian Council of Medical Research.

Conflicts of interest. All authors report no conflicts of interest relevant to this article.

\section{References}

1. Liu YY, Wang Y, Walsh TR, et al. Emergence of plasmid-mediated colistin resistance mechanism $m c r-1$ in animals and human beings in China: a microbiological and molecular biological study. Lancet Infect Dis 2016;16:161-168.

2. Aghapour Z, Gholizadeh P, Ganbarov K, et al. Molecular mechanisms related to colistin resistance in Enterobacteriaceae. Infect Drug Resist 2019;12:965-975.

3. Singh S, Pathak A, Kumar A, et al. Emergence of chromosome-borne colistin resistance gene $m c r-1$ in clinical isolates of Klebsiella pneumoniae from India. Antimicrob Agents Chemother 2018;62:pii:e01885-17.

4. Pragasam AK, Shankar C, Veeraraghavan B, et al. Molecular mechanisms of colistin resistance in Klebsiella pneumoniae-causing bacteremia from India—a first report. Front Microbiol 2017;7:2135-2143.

5. Poirel L, Jayol A, Nordmann P. Polymyxins: antibacterial activity, susceptibility testing, and resistance mechanisms encoded by plasmids or chromosomes. Clin Microbiol Rev 2017;30:557-596.

6. Du H, Chen L, Tang YW, Kreiswirth BN. Emergence of the mcr-1 colistin resistance gene in carbapenem-resistant Enterobacteriaceae. Lancet Infect Dis 2016;16:287-288.

7. Xavier BB, Lammens C, Ruhal R et al. Identification of a novel plasmidmediated colistin-resistance gene, mcr-2, in Escherichia coli, Belgium, June 2016. Euro Surveill 2016;21:30280.

8. Yin W, Li H, Shen Y, et al. Novel plasmid-mediated colistin resistance gene mcr-3 in Escherichia coli. MBio 2017;8:pii:e00543-17.

9. Carattoli A, Villa L, Feudi C, et al. Novel plasmid-mediated colistin resistance $m c r-4$ gene in Salmonella and Escherichia coli, Italy 2013, Spain and Belgium, 2015 to 2016. Euro Surveill 2017;22. pii: 30589.

10. Borowiak M, Fischer J, Hammerl JA, Hendriksen RS, Szabo I, Malorny B. Identification of a novel transposon-associated phosphoethanolamine transferase gene, $m c r-5$, conferring colistin resistance in d-tartrate fermenting Salmonella enterica subsp. enterica serovar Paratyphi B. J Antimicrob Chemother 2017;72:3317-3324.

\title{
Zagros Mountains: A region in Iran with extremely high incidence of Brucellosis
}

\author{
Milad Abdi $\mathrm{PhD}^{1,2}$, Rasoul Mirzaei $\mathrm{PhD}^{3}$, Vahid Lohrasbi $\mathrm{PhD}^{2}$ and Khosrow Zamani $\mathrm{PhD}^{2}$ \\ ${ }^{1}$ Student Research Committee, Faculty of Medicine, Iran University of Medical Sciences, Tehran, Iran, ${ }^{2}$ Department of Microbiology, Faculty of Medicine, \\ Iran University of Medical Sciences, Tehran, Iran and ${ }^{3}$ Department of Medical Microbiology, School of Medicine, Hamadan University of Medical Sciences, \\ Hamadan, Iran
}

To the Editor-Brucellosis, or Mediterranean fever, is an important zoonotic disease caused by various species of the gramnegative bacteria Brucella. The well-known species of Brucella are B. abortus, B. melitensis, B. ovis, B. canis, and B. suis, which infect cows, goats, sheep, dogs, and pigs, respectively. ${ }^{1}$ This infectious disease can be transmitted from infected animals to humans through direct contact, tissues (placenta or aborted tissues), or animal products (dairy products). Human to human transmission is rare. ${ }^{2}$ Brucellosis imposes considerable economic losses in many countries each year via damage to livestock through reduced fertility, abortion, and decline in milk production and via humans through significant loss of work days of infected persons and their families and long-term treatment costs. ${ }^{3}$ According to the World Health Organization, $>500,000$ new cases of brucellosis

Author for correspondence: Milad Abdi, Department of Microbiology, Faculty of Medicine, Iran University of Medical Sciences, Tehran, Iran. E-mail: miladabdi1369@ gmail.com

Cite this article: Abdi M, et al. (2020). Zagros Mountains: A region in Iran with extremely high incidence of Brucellosis. Infection Control \& Hospital Epidemiology, 41: 380-382, https://doi.org/10.1017/ice.2019.378 are reported annually worldwide; however, undetected cases are estimated to be $4 \times$ this number. ${ }^{4,5}$ The incidence rate of this infection varies from $<0.01$ to $>200$ cases per 100,000 population in different parts of the world, depending on geographical area, hygiene level, eating habits, occupation, and other factors. ${ }^{6}$ Notably, the incidence rate of this disease (per 100,000 population) is very low in many countries: the United States (0.04), Italy (0.9), Spain (1.3), Russia (0.4), Chile (0.006) France (0.05), South Korea $(0.1)$, and China (0.4). It has even been eradicated in some countries: Sweden, Denmark, Finland, Germany, the United Kingdom (excluding Northern Ireland), Austria, Netherlands, Belgium, Luxembourg, Norway, and Switzerland. Unfortunately, the infection is still endemic in Middle East countries, where high incidence rates (per 100,000 population) prevail: Iran (23.8), Turkey (26.2), Syria (160.3), Saudi Arabia (21.4), and Iraq (27.8). ${ }^{7}$ In Iran, $\sim 16,000$ cases of brucellosis are reported annually. ${ }^{8,9}$ According to data from the National Commission on Communicable Diseases Control, in 1989, the annual incidence exceeded 100 cases per 100,000 population, but in 2013 , the annual incidence had fallen to 23.8 cases per 100,000 population. Despite this decline, 